SSN 2519-7398 (Versión electrónica)

DOI: http://dx.doi.org/10.21704/ac.v78i2.1047

(C) Universidad Nacional Agraria La Molina, Lima - Perú

\title{
La balanza en cuenta corriente peruana en un contexto global
}

\author{
The peruvian current account balance in a global context
}

\author{
Silvia Rosa Pérez Huamán ${ }^{1}$
}

\begin{abstract}
Resumen
De la base de datos del Fondo Monetario Internacional para el periodo 2007 - 2015 se seleccionaron 122 países y se analizaron las características y tendencias de las subcuentas de la balanza en cuenta corriente por país, grupo de países y continentes, además de los Perfiles Comerciales 2016 de la Organización Internacional del Comercio, se estimaron los desequilibrios globales en la balanza en cuenta corriente como porcentaje del PBI por continente con la finalidad de determinar los "ganadores" y "perdedores" en el comercio global. Se concluye que aunque en el interior de cada continente hay países con déficit o superávit en cuenta corriente, en el intercambio comercial global Europa, Asia y Eurasia son los continentes con saldos netos positivos mientras que América y África son los continentes deficitarios demandantes de financiamiento externo.
\end{abstract}

Palabras clave: economía internacional; balanza en cuenta corriente; balanza de pagos.

\begin{abstract}
From the International Monetary Fund database for the period 2007-2015, 122 countries were selected and the characteristics and trends of the subaccounts of the current account balance by country, group of countries and continents were analyzed, furthermore, to the Trade Profiles 2016 of the International Trade Organization estimated the global imbalances in the current account balance as a percentage of GDP per continent in order to determine the "winners" and "losers" in global trade. It is concluded that although in the interior of each continent there are countries with current account deficits o surpluses, in global trade Europe, Asia and Eurasia are the continents with positive net balances while America and Africa are the deficient continents demanding external financing.
\end{abstract}

Keywords: international economy; current account balance; balance of payments.

\section{Introducción}

La balanza en cuenta corriente forma parte de la balanza de pagos de un país y brinda información muy útil sobre cómo un país interactúa con el resto del mundo. Sin embargo, un sostenido saldo negativo en la cuenta corriente genera desequilibrios y la necesidad de financiamiento sea éste interno o externo.

La balanza en cuenta corriente peruana registra las exportaciones e importaciones de bienes y servicios y tiene cuatro componentes: la balanza comercial, la balanza de servicios, la renta de factores y las transferencias corrientes. La balanza comercial (BC) registra el flujo neto de exportaciones e importaciones de mercancías y muestra una tendencia positiva pero finalmente decreciente a excepción del año 2016 que cerró con un superávit comercial. Esta característica responde a una mayor participación de las exportaciones pero también de las importaciones, cuyas brechas cada vez más pequeñas están acentuadas por la consolidación de los tratados de libre comercio en los cuales tenemos alrededor del $70 \%$ de las partidas arancelarias con arancel $0 \%$.

La balanza de servicios (BS) comprende el saldo neto por concepto de transporte (fletes), viajes, seguros y reaseguros y muestra una tendencia decreciente. A pesar que el rubro de viajes es positivo debido a la actividad turística, ésta no compensa a las demás cuentas.

La renta de factores (RF) es una cuenta de pagos e ingresos obtenido por rentas de capital o trabajo. En el caso peruano el saldo es negativo y responde básicamente a la salida neta de utilidades por inversión extrajera directa y en menor medida a los saldos netos de intereses por préstamos. Esta cuenta es sostenidamente negativa (Figura, 1).

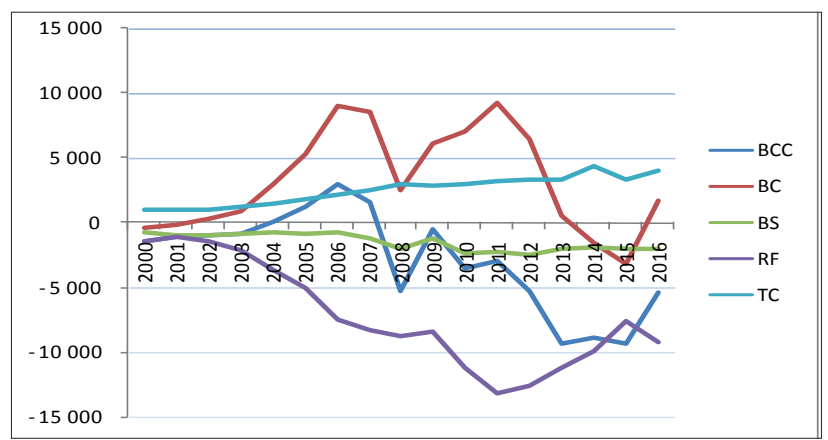

Figura 1. BCC peruana 2000 - 2016 (Mill.US\$)

Fuente: BCRP, 2016

\footnotetext{
${ }^{1}$ Facultad de Economía y Planificación, Universidad Nacional Agraria La Molina, Lima, Perú. E-mail: sperez@lamolina.edu.pe
} 
Las transferencias corrientes (TC) registran básicamente dos rubros netos, las donaciones y las remesas del exterior provenientes de las familias que laboran en el extranjero y cuyas remesas tienen su origen en países como EEUU, Chile, Italia y España (BCRP, 2016).

Finalmente, al sumar las cuatro cuentas se obtiene la balanza en cuenta corriente (BCC), cuyo saldo es persistentemente negativo. Esto significa que la balanza comercial y las transferencias corrientes, que son positivas, no compensan los saldos netos de la balanza de servicios y la renta de factores. Bajo estas condiciones los desequilibrios en la balanza en cuenta corriente peruana no son coyunturales sino estructurales.

En este contexto, surgen algunas preguntas que están relacionadas entre sí, ¿Tienen los demás países de América Latina los mismos problemas estructurales que presenta la cuenta corriente peruana? ¿Qué diferencias hay entre los saldos en cuenta corriente de países en vías de desarrollo, los emergentes y los desarrollados? ¿Cómo son los saldos globales a nivel de continentes? El propósito de este estudio fue analizar comparativamente las características y tendencias de la balanza en cuenta corriente peruana en un contexto mundial con la finalidad de determinar los "ganadores" y "perdedores" en el comercio global.

\section{Materiales y método}

Para responder a las preguntas de investigación planteadas se utilizó la base de datos en formato Excel del Fondo Monetario Internacional desde los años 2007 hasta 2015, la cual da cuenta de información de la estructura de exportaciones e importaciones relacionadas a las subcuentas de balanza en cuenta corriente expresadas en millones de dólares. Se seleccionó la información consistente y continua de 122 países (37 países de Europa, 9 países de Eurasia, 15 países de Asia Este y Pacífico, 6 países de Asia Sur, 21 países de América Latina y El Caribe, 2 países de América del Norte, 10 países de África del Este Medio y Norte y 22 países de África Sub-Sahara). Los datos se procesaron por país, por grupo de países y luego por continente.

Con esta misma clasificación pero para el año 2016 y en base al Perfil Comercial 2016 de la Organización Internacional del Comercio se procesaron los desequilibrios globales de la balanza en cuenta corriente expresados como porcentaje del PBI tanto a nivel de país como a nivel de grupo de países y por continente. Para los datos del 2016, se disponía de información adicional de 5 países de África del Este Medio y Norte y de 7 países de África Sub-Sahara, los cuales fueron incluidos en el cómputo sólo para 2016 con la finalidad de mejorar los cálculos de los desequilibrios globales para este año, totalizando 134 países para el año 2016. Asimismo, se procesó información por países del Índice de Competitividad Global 2016 del Foro Económico Mundial a fin de indagar sobre las fortalezas y/o debilidades de los pilares de la competitividad relacionados con el comercio global.
Los figuras consolidados se presentaron por cada subcuenta de la balanza en cuenta corriente y a la vez por continente, mientras que los desequilibrios globales por cada grupo de países y por continente.

\section{Resultados y discusión}

Al procesar la información por país, por grupo de países y después por continente se observa que en cada continente los países más exitosos en materia de comercio no siempre compensan los déficits de los países con menos éxito en su balanza en cuenta corriente.

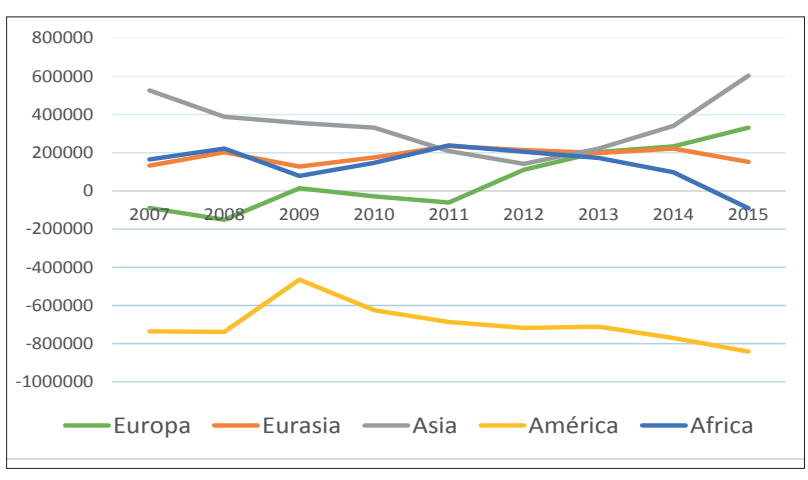

Figura 2. La BC 2007 - 2015 (Mill.US\$)

La BC es más sostenida en Europa, pues muestra una tendencia creciente principalmente por los países de la Euro Zona, destacando como exportadores netos Alemania, Irlanda y Países Bajos y como los mayores importadores netos Reino Unido, Turquía y Francia.

Al otro extremo se ubican los países de América, quienes poseen una balanza comercial negativa debido a la presencia de EEUU como el mayor importador neto y que en conjunto contrae los efectos positivos de algunos países exportadores netos como Canadá, Brasil, Chile, Paraguay y Venezuela, entre otros.

La BC de Eurasia se mantiene positiva y relativamente estable, sostenida por las exportaciones netas de Rusia, Kazajstán y Azerbaiyán mientras que los mayores importadores netos son Georgia, Ucrania y Tayikistán. Por su parte, la BC de Asia es positiva y creciente, debido a que las exportaciones netas de los países de Asia Este y Pacífico como China, Corea, Singapur, Tailandia e Indonesia compensaron las importaciones netas de los países del Asia Sur como India, Pakistán, Sri Lanka y Bangladesh.

En el caso de los países africanos a pesar que tienen una BC positiva, ésta decreciente desde el 2013 y se hace negativa al 2015, debido a las menores importaciones de los países del África este medio y norte como Arabia Saudita y Omán, los cuales no compensaron las importaciones netas provenientes de Etiopía, Nigeria y Tanzania, principalmente.

El saldo de BS de Europa y América es tradicionalmente positiva y creciente. En el caso de América, EEUU neutraliza y compensa los saldos negativos de los países de América Latina. Sin embargo, los países de Eurasia, 
Asia y África mantienen saldos negativos de la balanza de servicios.

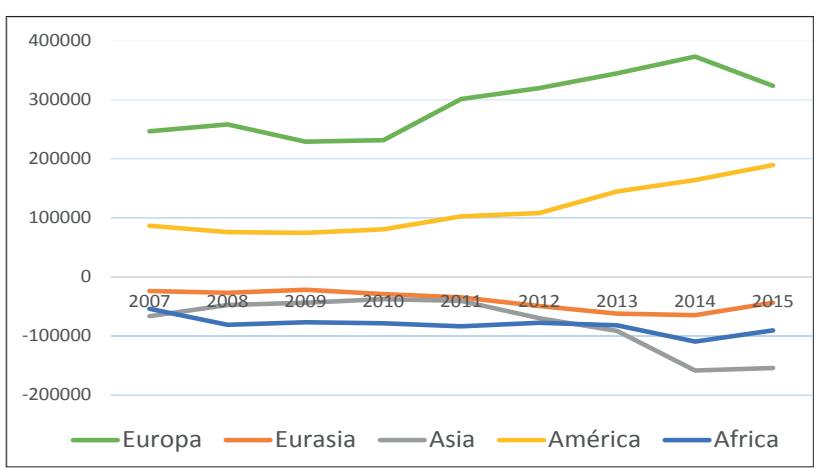

Figura 3. La BS 2007 - 2015 (Mill. US\$)

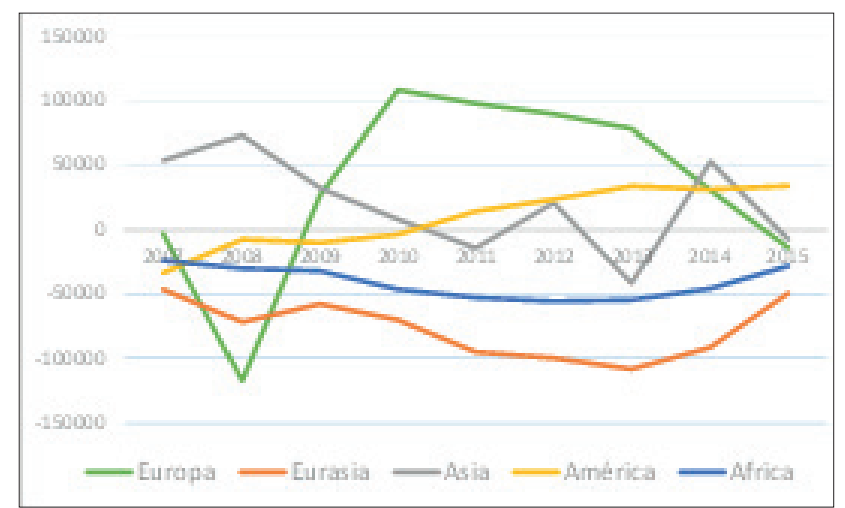

Figura 4. La RF 2007 - 2015 (Mill. US\$)

El saldo de la RF europea es positiva y se sostiene con las exportaciones netas de Alemania, Francia y Noruega principalmente, siendo Irlanda, Reino Unido y Luxemburgo los países de mayor saldo negativo.

En América, EEUU mantiene una RF creciente y positiva y compensa los saldos netos negativos de los países latinos como Brasil, Argentina, Perú y Chile. Por otro lado, los países de Asia Este y Pacífico ostentan saldos positivos en la cuenta de RF en comparación a las cuentas negativas de los países de Asia del Sur y los de Eurasia.

Las TC netas positivas al ser el resultado de las donaciones y envío de remesas del exterior son de vital importancia para los países del Asia Sur, América Latina y El Caribe, África Sub Sahara y en menor medida a los países de Asia del Este y Pacífico y África del Este Medio y Norte.

Las TC netas negativas provienen de Europa y América del Norte con países como Francia, Alemania, Suiza, Reino Unido, España, EEUU y Canadá. Estas transferencias se dan desde Europa y América del Norte hacia Asia Sur, América Latina y El Caribe y África Sub Sahara.

Finalmente, la BCC de Europa, Asia y Eurasia muestran superávit, en comparación de los países africanos que sus saldos positivos sólo se mantienen hasta el 2013 en que empiezan a ser negativos. Para el caso de América, la situación es muy crítica, tanto los países de América Latina y El Caribe así como EEUU y Canadá, aunque en diferente escala, muestran una sostenida caída de la balanza en cuenta corriente.

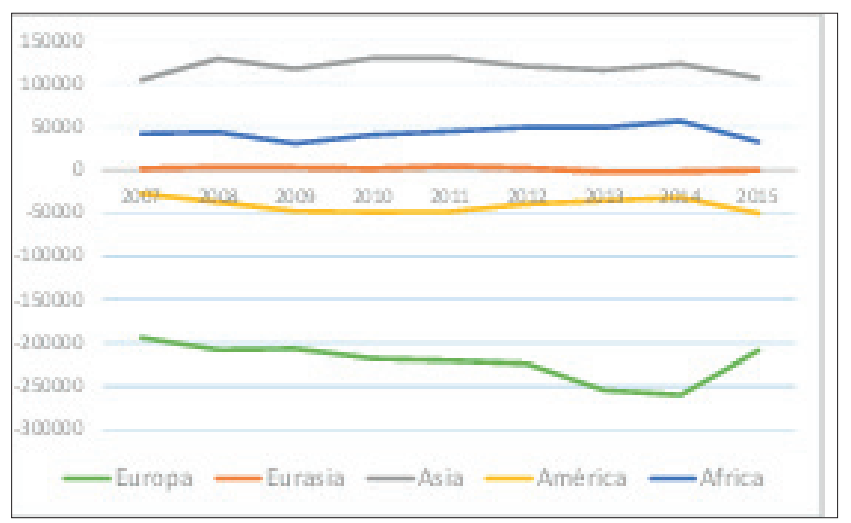

Figura 5. Las TC 2007 - 2015 (Mill. US\$)

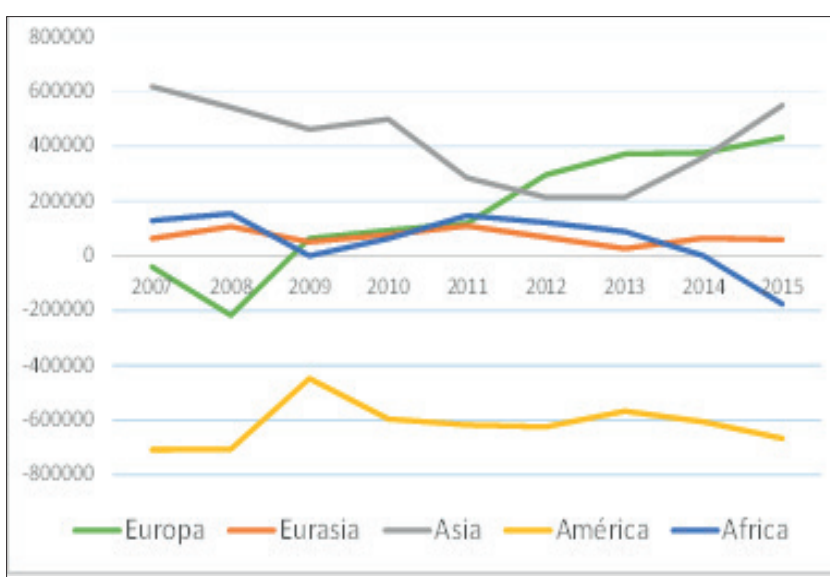

Figura 6. La BCC 2007 - 2015 (Mill. US\$)

A este nivel es posible plantearse la pregunta de cómo se distribuye la renta proveniente del comercio internacional. $\mathrm{Y}$ es que como afirma el modelo de Factores Específicos propuesto por Samuelson (Krugman, 2012), la apertura comercial genera ganadores y perdedores en el comercio y no es tan cierto que todos ganan en el comercio global. En términos históricos se aprecia que Europa, Asia y en menor medida Eurasia serían los "ganadores" mientras que América y África, en menor medida, los "perdedores". En el caso peruano, la BCC es persistentemente negativa por lo Perú conformaría parte de los "perdedores" en el comercio global". Sin embargo, es preciso complementar el análisis de las subcuentas de la BCC a nivel de continente para tener una visión más clara de cómo se gestionan o se sostienen las BCC en cada grupo de países.

La gestión de las subcuentas por continente muestra que Europa es el continente que mejor gestiona sus cuentas externas.

Su balanza en cuenta corriente no sólo es creciente sino que se sostiene con un saldo positivo de una importante balanza comercial y de servicios, con una contribución 
significativa de la renta de factores, las que en su conjunto financian las transferencias corrientes netas hacia otros países.

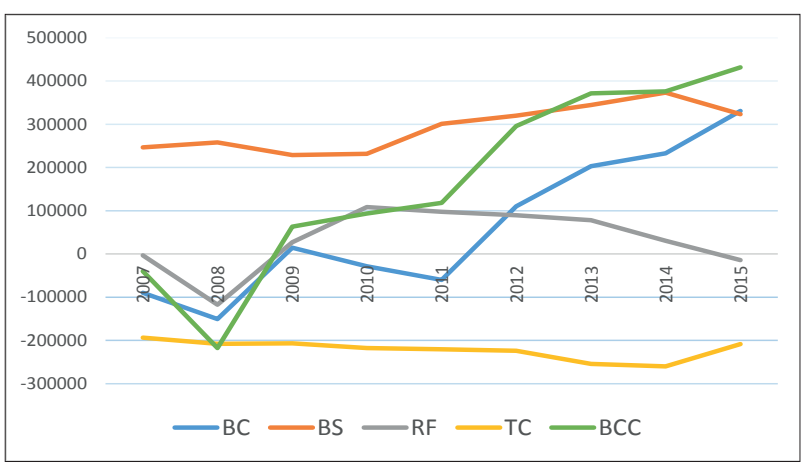

Figura 7. BCC en Europa 2007 - 2015 (Mill.US\$)

A diferencia, la gestión de las cuentas externas en Eurasia consiste en un impresionante apoyo de la balanza comercial que es capaz de financiar los saldos negativos de la balanza de servicios y la renta de factores, logrando una balanza en cuenta corriente positiva pero no muy estable.

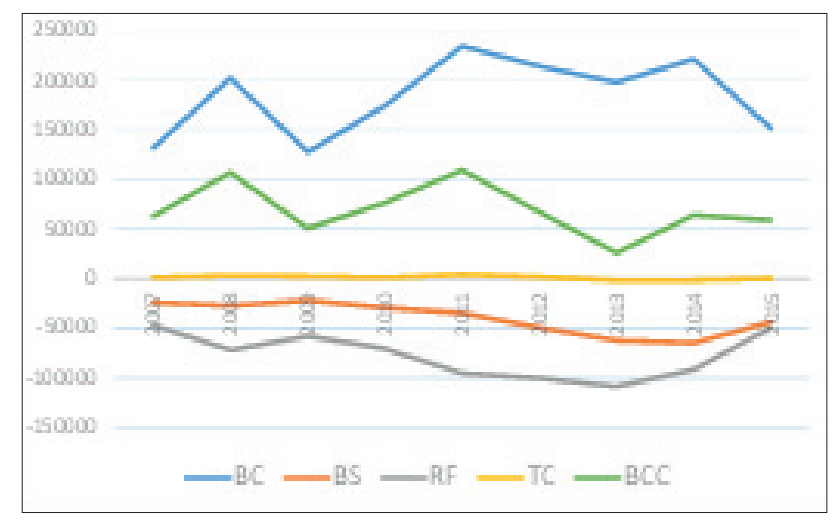

Figura 8. BCC en Eurasia 2007 - 2017 (Mill.US\$)

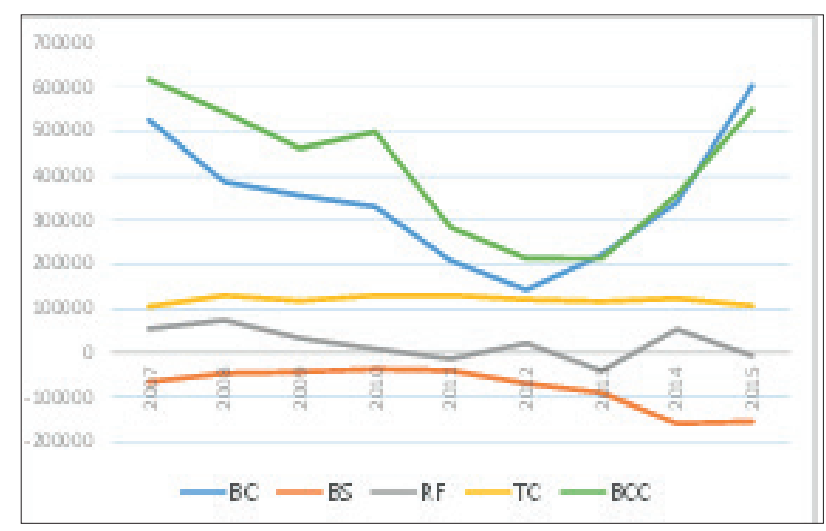

Figura 9. BCC en Asia 2007 - 2017 (Mill.US\$)
Por su parte, Asia rompe la tendencia decreciente pero positiva de su balanza en cuenta corriente a partir del 2012 y la mantienen creciente y de manera sostenida. Su gestión de las cuentas externas también está basada en la balanza comercial y en menor medida, en las Transferencias corrientes y la renta de factores, las cuales permiten financiar con holgura el saldo negativo de la balanza de servicios.

América en su conjunto posee una gestión de sus cuentas externas muy particular debido a la importancia de EEUU en el territorio.

América Latina es exportadora neta de mercancías y receptora neta de transferencias corrientes, pero estos resultados positivos se neutralizan con un excesivo saldo negativo de la balanza de servicios y de la renta de factores, con lo cual es imposible esperar una balanza en cuenta corriente sostenida y positiva.

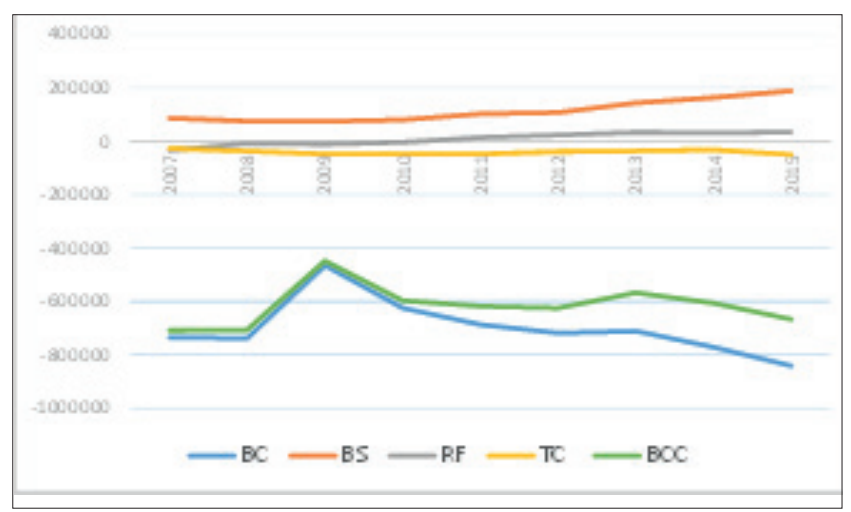

Figura 10. BCC en América 2007 - 2017 (Mill.US\$)

Los países del Caribe muestran otro tipo de gestión. Al ser exportadores netos de servicios, principalmente turísticos, y receptores netos de transferencias corrientes, sus saldos positivos no logran compensar el persistente déficit de la balanza comercial y de la renta de factores, motivo por el cual también ostentan un persistente y sostenido déficit en balanza en cuenta corriente. Mientras tanto los países de América del Norte, EEUU y Canadá, son exportadores netos de las cuentas de balanza de servicios y la renta de factores, cuyos niveles no cubren las transferencias corrientes netas ni la balanza comercial que son deficitaria, por lo que su balanza en cuenta corriente es negativa pero estable y controlada.

De manera similar sucede con los países africanos, siendo los países de África del Este Medio y Norte los que compensan el déficit de los países de África del SubSahara.

Los saldos de la balanza en cuenta corriente de los países africanos no se aprecian sostenidamente negativos, ya que están respaldadas con las exportaciones netas de mercancías y las transferencias corrientes netas positivas, las cuales en promedio cubren los saldos negativos de la balanza de servicios y la renta de factores, excepto en los años 2014 y 2015. 


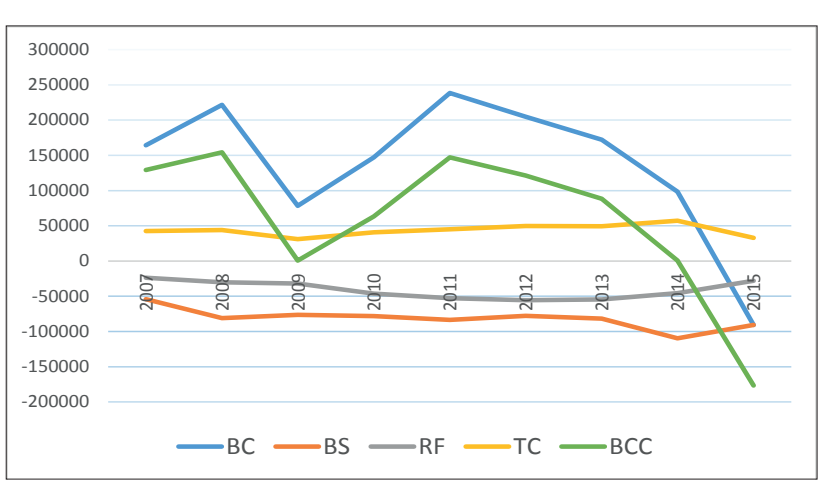

Figura 11. BCC en África 2007 - 2017 (Mill.US\$)

Sin embargo, una visión desagregada de las cuentas muestra a los países del Sub Sahara con balanzas en cuenta corriente sostenidamente decrecientes y negativas en todo el periodo de estudio, que también responden a saldos sostenidamente negativos en la balanza comercial, de servicios y renta de factores, siendo las transferencias corrientes la única cuenta positiva.

Frente a este panorama se espera que los desequilibrios en la balanza en cuenta corriente sean muy diferenciados por países, grupo de países y por continente. En la Tabla 1 se presenta una síntesis de los cálculos estimados por país y grupo de países y en el Figura 12 los resultados por continentes.

El $62 \%$ de los países europeos ostentan un superávit en cuenta corriente y financian el déficit de los países con déficit, puesto que a nivel global también se obtiene un superávit que bordea el $2.4 \%$ del PBI continental. El nivel más alto de superávit en cuenta corriente lo tiene Suiza con un $12 \%$ de su PBI. En las demás categorías se detallan los resultados por grupo de países según el nivel de superávit y/o déficit.

Entre los países de Eurasia, la situación es preocupante puesto que sólo Rusia presenta superávit en cuenta corriente que asciende a $1.7 \%$ del PBI, por lo que el resto de países presentan diferentes niveles de desequilibrios en cuenta corriente. Sin embargo, en términos globales, Eurasia presenta un superávit del $0.4 \%$ del PBI continental.

El 33\% de los países de Asia sur experimentan superávit en cuenta corriente, lo cual no compensa a los países con déficit ya que a nivel de grupo de países enfrentan un desequilibrio de $0.8 \%$ del PBI. Por su parte el $60 \%$ de los países de Asia Este y Pacífico gozan de superávit en cuenta corriente y a nivel de grupo de países han conseguido un superávit del 2.6\% del PBI. A nivel global, Asia muestra un superávit en cuenta corriente de $2.2 \%$ del PBI continental.

En el caso de los países de América se aprecia un desequilibro global del $2.65 \%$ del PBI continental. De los 23 países, solo 3 países de América Latina y El Caribe obtienen superávit en cuenta corriente, por lo que a nivel grupo de países América Latina y El Caribe enfrentan un desequilibrio en cuenta corriente de $2.1 \%$ de su PBI y en América del Norte un déficit del $2.7 \%$ de su PBI Finalmente, los países africanos como continente enfrentan un desequilibrio global en cuenta corriente de $2.69 \%$ de su PBI continental. Esto significa que el $10 \%$ de los países africanos del Sub-Sahara y el $27 \%$ de la zona del Este medio y Norte de África que poseen superávit en cuenta corriente no compensan el déficit en cuenta corriente de los demás países de la región.

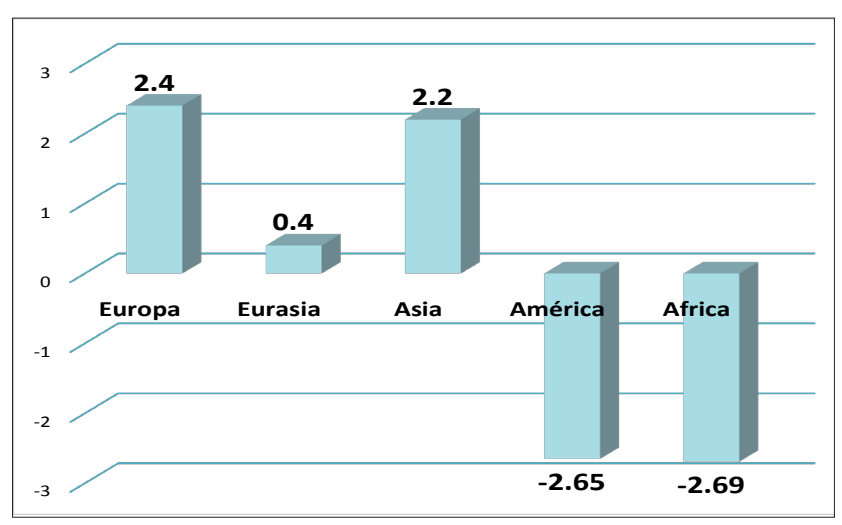

Figura 12. Desquilibrios globales en BCC 2016 (\% PBI)

Con estos desequilibrios globales para el año 2016, se aprecia claramente que Europa, Asia y Eurasia con 2.4\%, $2.2 \%$ y $0.8 \%$ del PBI continental respectivamente son los "ganadores" del comercio global mientras que América y África con déficit en cuenta corriente de $2.65 \%$ y $2.69 \%$ del PBI continental respectivamente son los "perdedores" del comercio global.

Dentro del conjunto de países estudiados, se han elegido algunos países emblemáticos por los éxitos en la gestión de su balanza en cuenta corriente y otros en los cuales el déficit en cuenta corriente representa la presencia de serios problemas estructurales. Para ello se sistematizado el Índice de Competitividad Global 2016 (ICG), que computa un índice ponderado que oscila entre 0 y 7 , cuanto más cercano a 7 más competitivo es el país; además se ha desagregado 5 pilares del índice general que están relacionados con el comercio global (instituciones, infraestructura, estabilidad macroeconómica, preparación tecnológica e innovación), los cuales se muestran en la Tabla 2.

Los países más desarrollados son los que poseen los más altos ICG como Singapur, Países Bajos, Alemania y Japón, que tienen los niveles más altos en los 4 pilares, pero destacan principalmente por la infraestructura y la preparación tecnológica. Mientras que aquellos países emergentes como Israel, Corea, China, Tailandia y Rusia centran sus ventajas en la infraestructura y la estabilidad macroeconómica. La preparación tecnológica y la innovación son todavía tareas pendientes en especial para Tailandia y Rusia.

Países como Botsawa, Nepal y Bangladesh poseen un mejor avance en la estabilidad macroeconómica y su balanza en cuenta corriente es positiva debido a que las transferencias corrientes y la balanza de servicios cubren una controlada renta de factores, que en conjunto tratan de cubrir una significativa balanza comercial. 
Tabla 1. Desequilibrios globales de la BCC e IGC 2016

\begin{tabular}{|c|c|c|c|c|c|}
\hline \multirow[b]{2}{*}{ Zonas } & \multirow[b]{2}{*}{ Países } & \multirow{2}{*}{$\begin{array}{c}\mathrm{N}^{\circ} \\
\text { países }\end{array}$} & \multicolumn{3}{|c|}{$\mathrm{BCC}(\% \mathrm{PBI})$} \\
\hline & & & Max & Min & Total \\
\hline \multirow{5}{*}{ Europa } & $\begin{array}{l}\text { Suiza, Países Bajos, Alemania, Dinamarca, Islandia, } \\
\text { Eslovenia, Malta }\end{array}$ & 7 & 12.0 & 5.8 & \multirow{5}{*}{2.4} \\
\hline & $\begin{array}{l}\text { Luxemburgo, Suecia, Irlanda, Noruega, Hungría, Bulgaria, } \\
\text { Croacia }\end{array}$ & 7 & 4.8 & 3.9 & \\
\hline & $\begin{array}{l}\text { Estonia, Italia, España, Letonia, Rep. Checa, Bélgica, } \\
\text { Portugal, Rep. Eslovaca }\end{array}$ & 9 & 2.7 & 0.4 & \\
\hline & $\begin{array}{l}\text { Polonia, Grecia, Lutuania, Finlandia, Francia, Rumania, } \\
\text { Chipre }\end{array}$ & 7 & -2.4 & -0.3 & \\
\hline & $\begin{array}{l}\text { Macedonia FyR, Turquía, Serbia, Reino Unido, } \\
\text { Boznia\&G, Albania, Montenegro }\end{array}$ & 7 & -19.1 & -3.1 & \\
\hline \multirow{3}{*}{ Eurasia } & Rusia & 1 & 1.7 & 1.7 & \multirow{3}{*}{0.4} \\
\hline & Armenia, Moldavia, Ucrania, Azerbaiyán & 4 & -3.8 & -2.9 & \\
\hline & Tayikistán, Kazajstán, Kirguistán, Georgia & 4 & -12.4 & -5.1 & \\
\hline \multirow{3}{*}{ Asia sur } & Nepal, Bangladesh & 2 & 6.3 & 0.9 & \multirow{3}{*}{-0.8} \\
\hline & India, Pakistan, Sri Lanka & 3 & -2.3 & -0.9 & \\
\hline & Buthan & 1 & -29.1 & -29.1 & \\
\hline \multirow{4}{*}{$\begin{array}{l}\text { Asia este } \\
\& \text { pacífico }\end{array}$} & Singapur, Tailandia, Corea, Hong Kong & 4 & 19.0 & 5.1 & \multirow{4}{*}{2.6} \\
\hline & Vietnam, Japón, Malasia, China, Filipinas & 5 & 4.7 & 0.2 & \\
\hline & Indonesia, Australia, Nueva Zelanda & 3 & -2.7 & -1.8 & \\
\hline & Mongolia, Camboya, Laos & 3 & -17.0 & -4.1 & \\
\hline \multirow{3}{*}{$\begin{array}{l}\text { América L. y } \\
\text { El Caribe }\end{array}$} & Ecuador, Guatemala, Paraguay & 3 & 1.1 & 0.6 & \multirow{3}{*}{-2.1} \\
\hline & $\begin{array}{l}\text { Urugay, Brazil, Chile, Rep. Dominicana, Venezuela, El } \\
\text { Salvdor, Argentina, México, Jamaica, Perú }\end{array}$ & 10 & -2.8 & -1 & \\
\hline & $\begin{array}{l}\text { Costa Rica, Honduras, Colombia, Bárbados, Panamá, } \\
\text { Bolivia, Trinidad y Tobago, Nicaragua }\end{array}$ & 8 & -9.5 & -3.5 & \\
\hline \multirow{3}{*}{$\begin{array}{l}\text { América del } \\
\text { Norte }\end{array}$} & EEUU & 1 & -2.6 & -2.6 & \multirow[b]{2}{*}{-2.7} \\
\hline & Canadá & 1 & -3.3 & -3.3 & \\
\hline & Botsawa, Namibia, Nigeria & 3 & 14.7 & 0.6 & \multirow{4}{*}{-5.2} \\
\hline \multirow{3}{*}{$\begin{array}{l}\text { Africa Sub- } \\
\text { Sahara }\end{array}$} & $\begin{array}{l}\text { Zimbawe, Costa de M., Madagascar, Sud Africa, Camerún, } \\
\text { Mauricio }\end{array}$ & 6 & -4.3 & -1.6 & \\
\hline & $\begin{array}{l}\text { Kenia, Zambia, Uganda, Tanzania, Ghana, Cabo V., } \\
\text { Senegal, Benin, Lesoto, Mali, Gabón, Etiopía }\end{array}$ & 12 & -9.9 & -5.5 & \\
\hline & $\begin{array}{l}\text { Gambia, Ruanda, Malawi, Mauritania, Burundi, Sierra } \\
\text { Leona, Liberia, Mozambique }\end{array}$ & 8 & -38.9 & -10.1 & \\
\hline \multirow{2}{*}{$\begin{array}{l}\text { Africa este } \\
\text { medio \& norte }\end{array}$} & Irán, Israel, Kuwait, Emiratos Arabes & 4 & 6.3 & 2.4 & \multirow[b]{2}{*}{-2.0} \\
\hline & $\begin{array}{l}\text { Jordania, Katar, Arabia Saudita, Marruecos, Bahrein, } \\
\text { Egipto, Yemen, Tunesia, Oman, Líbano, Algeria }\end{array}$ & 11 & -16.4 & -1.4 & \\
\hline
\end{tabular}

Fuente: World Economic Forum, World Trade Organization Elaboración: Propia

EEUU y Canadá tienen buenos niveles de competitividad pero con saldos negativos en la balanza en cuenta corriente, sus fortalezas son la preparación tecnológica e infraestructura. Mientras que Chile, India y Sud África tienen sus fortalezas en la estabilidad macroeconómica y en menor medida la preparación tecnológica y niveles bajos en innovación.

En los demás países como Colombia, Perú, Brazil, Argentina, Etiopía, Egipto y Nigeria, hay mayor estabilidad macroeconómica, pero niveles aún bajos en instituciones, infraestructura e innovación.

\section{Conclusiones}

Sobre la interrogante de si los demás países de América Latina tienen los mismos problemas estructurales que presenta la cuenta corriente peruana, pues la respuesta es sí, en diverso grado, pero la mayoría soportan una balanza de servicios y una renta de factores creciente y negativa, pues las tendencias son muy claras. Al no ser una característica coyuntural, se concluye que es preciso corregir los problemas estructurales de la balanza de pagos de América Latina para reducir los desequilibrios en cuenta corriente y mejorar competitividad de los países en el comercio internacional. El buen manejo de la balanza en cuenta corriente de algunos países europeos y asiáticos puede servir de experiencias para los demás países, es decir el estudio de casos de países desarrollados como Suiza, Alemania y Países Bajos con IGC muy altos o países emergentes como China, Japón, Corea y Rusia con buenos niveles de competitividad conseguidos en los últimos años. Los saldos en la balanza en cuenta corriente entre países desarrollados, emergentes y en vías de desarrollo son 
muy diferentes. El $62 \%$ de los países europeos mantienen saldos positivos entre el $12 \%$ y el $0.4 \%$ del PBI, mientras en Eurasia sólo Rusia está en superávit. En Asia el 52 \% de países están en superávit, los países emergentes como Singapur, Tailandia, Corea y Hong Kong con tasas muy altas, pero con importantes desequilibrios en los países del Asia Sur. En los casos de países de América Latina y El Caribe y los países del África Sub-Sahara predominan un déficit sostenido, para América Latina sostenido en el déficit de la balanza de servicios y la renta de factores y para África en el déficit de la balanza comercial.

Tabla 2. Índice de competividad global 2106

\begin{tabular}{|c|c|c|c|c|c|c|c|}
\hline Países BCC (+) & Ranking & ICG & 1 & 2 & 3 & 9 & 12 \\
\hline Singapur & 2 & 5.72 & 6.1 & 6.5 & 6.1 & 6.1 & 5.3 \\
\hline Países Bajos & 4 & 5.57 & 5.7 & 6.4 & 5.7 & 6.2 & 5.4 \\
\hline Alemania & 5 & 5.57 & 5.2 & 6.1 & 6.0 & 6.1 & 5.6 \\
\hline Japón & 8 & 5.48 & 5.4 & 6.3 & 4.1 & 5.8 & 5.4 \\
\hline Israel & 24 & 5.18 & 4.8 & 5.3 & 5.1 & 5.8 & 5.7 \\
\hline Corea & 26 & 5.03 & 4.0 & 6.0 & 6.6 & 5.5 & 4.8 \\
\hline China & 28 & 4.95 & 4.3 & 4.7 & 6.2 & 4.0 & 4.0 \\
\hline Tailandia & 34 & 4.64 & 3.7 & 4.4 & 6.1 & 4.3 & 3.4 \\
\hline Rusia & 43 & 4.51 & 3.6 & 4.9 & 4.3 & 4.3 & 3.4 \\
\hline Botsawa & 64 & 4.29 & 4.5 & 3.5 & 6.2 & 3.6 & 3.2 \\
\hline Nepal & 98 & 3.87 & 3.5 & 2.2 & 5.5 & 2.6 & 2.6 \\
\hline Bangldesh & 106 & 3.80 & 3.1 & 2.8 & 4.8 & 2.7 & 2.8 \\
\hline Países BCC (-) & Ranking & ICG & 1 & 2 & 3 & 9 & 12 \\
\hline EEUU & 3 & 5.70 & 5.0 & 5.9 & 4.6 & 6.0 & 5.6 \\
\hline Canádá & 15 & 5.27 & 5.4 & 5.7 & 5.2 & 5.8 & 4.6 \\
\hline Chile & 33 & 4.64 & 4.5 & 4.7 & 5.4 & 5.1 & 3.4 \\
\hline India & 39 & 4.52 & 4.4 & 4.0 & 4.5 & 3.0 & 4.0 \\
\hline Sud Africa & 47 & 4.47 & 4.5 & 4.2 & 4.5 & 4.7 & 3.8 \\
\hline Colombia & 61 & 4.30 & 3.3 & 3.7 & 5.0 & 4.3 & 3.3 \\
\hline Perú & 67 & 4.23 & 3.4 & 3.6 & 5.4 & 3.6 & 2.8 \\
\hline Brazil & 81 & 4.06 & 3.2 & 4.0 & 3.5 & 4.4 & 3.1 \\
\hline Argentina & 104 & 3.81 & 3.0 & 3.7 & 2.9 & 4.1 & 3.2 \\
\hline Etiopía & 109 & 3.77 & 3.9 & 2.8 & 4.5 & 2.4 & 3.4 \\
\hline Egipto & 115 & 3.67 & 3.6 & 3.4 & 2.7 & 3.3 & 2.7 \\
\hline Nigeria & 127 & 3.39 & 3.3 & 2.1 & 4.0 & 3.1 & 2.9 \\
\hline Nota: & & & \multirow{3}{*}{\multicolumn{5}{|c|}{$\begin{array}{l}\text { 9: Preparación tecnológica } \\
\text { 12: Innovación }\end{array}$}} \\
\hline 1: Instituciones & & & & & & & \\
\hline 2: Infraestructura & & & & & & & \\
\hline
\end{tabular}

Fuente: The Global Competitiveness Report 2016 - 2017 Report. World Economic Forum.

\section{Literatura citada}

Banco Central de Reserva del Perú - BCRP. 2016.. Memoria BCRP. 2016. Lima, Perú. Recuperado de www.bcrp.gob.pe

International Monetary Fund - IMF. 2016. Recuperado de www.imf.org

Krugman, P. y Obstfeld, M. 2012. “Economía Internacional. Teoría y Política".
Schwab, K.. and Sala-i-Martín, X. 2016. The Global Competitiveness Report 2016 - 2017. Insight Report. World Economic Forum.

World Trade Organization - WTO. 2017. Trade profiles 2017. Switzerland. Recuperado de www.wto.org 